\title{
Compare Between Gait Analysis of Patient with Ilizarov Leg and Prosthesis Leg
}

\author{
Omyia Mahmoud Jawad ${ }^{1}$, Sadiq Jaffar Abass ${ }^{2 *}$, Safa Kadiam Dia'a ${ }^{3 *}$
}

\author{
Authors affiliations: \\ 1) Biomedical Eng. Dept., Al-Nahrain \\ University, College of Engineering, \\ Baghdad, Iraq. \\ omgh444@gmail.com
}

2*) Biomedical Eng. Dept., Al-Nahrain University, College of Engineering, Baghdad, Iraq.

sadiq hamandi@,eng.nahrainuniv.edu.ic

3*) Medical City, Baghdad-Iraq. safaadiaa@yahoo.com

\section{Paper History:}

Received: $3^{\text {rd }}$ Dec. 2019

Revised: 30th Dec. 2019

Accepted: $16^{\text {th }}$ July 2020

\begin{abstract}
Gait analysis can be described as a field of biomechanical engineering dealing with the subject of human locomotion. This study aimed to identify the effect of Ilizarov on gait when the presence the above-knee prosthesis. The study was made on a 50-year-old male patient was underwent correction right tibia with Ilizarov fixation due to war accident in July 2012. Also, this accident led to trans-femoral amputation. Two-dimensional gait system of a synchronized $25 \mathrm{~Hz}$ camera with an AMTI force platform was use for measuring gait kinematics and kinetics data while walking at a self-selected speed. These data can be used as standard measures in pathology studies, as input to theoretical joint models, and as input to mechanical joint simulators treated with Ilizarov and prosthetics.
\end{abstract}

Keywords: Ilizarov, Trans-Femoral Amputation, Prosthesis, Kinematics, Kinetics.

\section{Introduction}

External fixation for the purpose of bony reuniformity has been in practice ago the early 1900s and is vastly used today. External fixators are firstly used for trauma but may as well be used for disfigurement correction and arthrodesis [1]. There are types many of external fixation devices commercially available. One of which is the Ilizarov frame, a modular system that can be tailored for both the patient and the fracture. Ilizarov frames are consist of comparatively hard metal rings linked by threaded rods, with each ring connected to bone by relatively flexible pins or wires. The use of relatively flexible pins and wires permit some load to be transferred to the bone on weight bearing, resulting in potentially beneficial mechanical stimulation of healing bone [2]. Through weight bearing, tensioned wires hold the fractured bone in the required alignment while allowing for pivotal movement at the fracture area. This pivotal micro-motion has been explained to enhance callus formation and lastly bone healing [3].

Tibial fracture accounts for the of all long bone fractures and is routinely handle with external fixation when complex [4,5]. Tibial fracture patients handle with Ilizarov frames show abnormal gait patterns for a diversity of reasons [6].

Lower limb amputation not only impact people's capability of walk, but may effects on their participation in valued activities, body image perception and quality of life [7]. However, quality of life post lower limb amputation is significantly associated with mobility, decreased capability of walk with a prosthesis is related with lower activities of daily life scores and a bring down level of social activity $[8,9,10,11]$.

Prosthetic devices have been used for centuries to assist amputees in preserving their quality of life and assist in their activities of daily living [12].

The objective of this study is biomechanical adaptations to gait for patient treated with Ilizarov, and he has prosthesis in other the limb due to trans-femoral amputation.

\section{Case study}

A 50 -year-old, height $1.7 \mathrm{~m}$ and body mass $87 \mathrm{~kg}$ male patient was injured in a war accident in July 2012. He was admitted to a local hospital, where The accident led to amputation above the left knee, Comminuted fracture of his right tibia leg and fracture in femur bone in same limb.

In beginning of injury the tibia bone is treated with unilateral external fixation for six months; but this method not correction bone as shown in Fig.1.

NJES is an open access Journal with ISSN 2521-9154 and eISSN 2521-9162

This work is licensed under a Creative Commons Attribution-NonCommercial 4.0 International License 


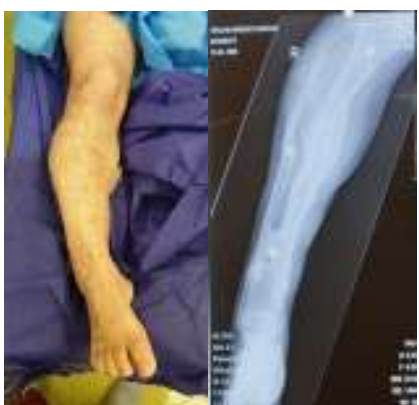

Figure (1): Right limb before Ilizarov operation

The femur bone treated with internal fixation and still for now as shown Fig.2.

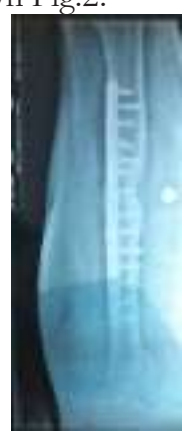

Figure (2): femur bone with internal fixation

The patient is use above-knee prosthesis in left limb made of polypropylene, and this prosthesis classify as single axis knee lock (SAK LOCK) and single axis cushion heel (SACH) as shown in Fig.3. In April 2019, the patient's Ilizarov surgery was performed for correction tibia bone as shown Fig.4.

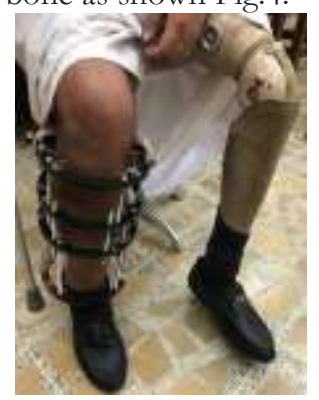

Figure (3): Left limb with prosthesis

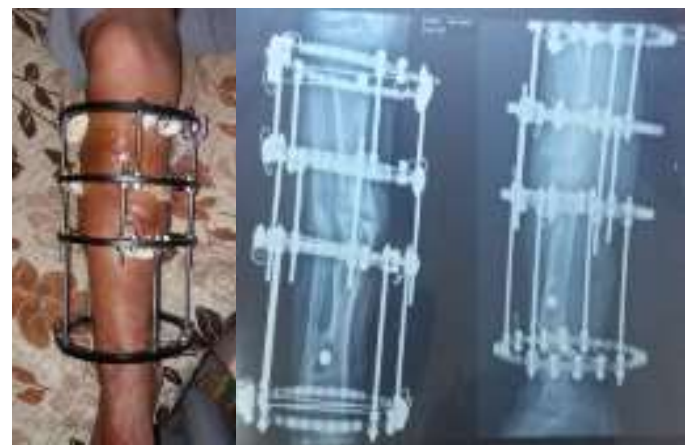

Figure (4): Right limb with Ilizarov external fixation

\section{Methodology}

\subsection{Kinematic Data}

The measurements of joint position, which is used for computing the joint angular displacement (joints relative angles), are obtained from the two dimensions motion analysis system. The joint positions are converted into joint absolute angles using the tangent function. The general equations for measuring the absolute angle is [17]:

$$
\theta i j=\operatorname{tang}^{-1}\left(\frac{Y j-Y i}{X j-X i}\right)
$$

The relative angles were determined as followed [17], Fig.5 :

$$
\begin{aligned}
& \text { Ankle angle }(\theta \mathrm{a})=\theta 1-\theta 2-90 \\
& \text { Knee angle }(\theta \mathrm{k})=\theta 3-\theta 2 \\
& \text { Hip angle }(\theta \mathrm{h})=\theta 3-\theta 4
\end{aligned}
$$

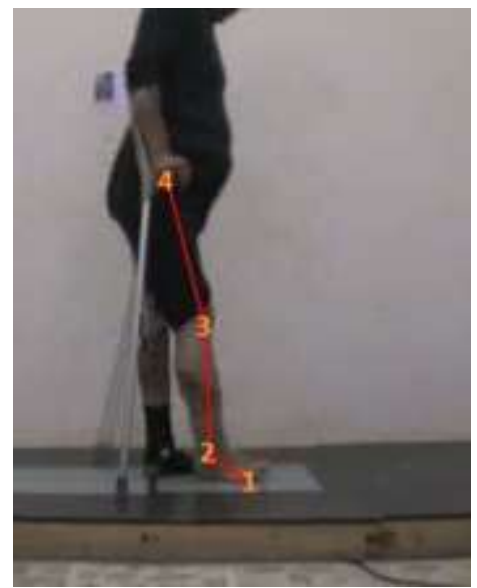

Figure (5): Marker's positions being digitized during a subject walking trials, and the angles are calculated from them.

The center of mass location (Xcg, Ycg) of each segment is estimated from the $(\mathrm{x}, \mathrm{y})$ marker coordinates (joints positions data) from the equations [18]:

$X_{c g}=X_{\text {proximal }}+R_{\text {proximal }}\left(X_{\text {distal }}-X_{\text {proximal }}\right)$

$Y_{c g}=Y_{\text {proximal }}+R_{\text {proximal }}\left(Y_{\text {distal }}-Y_{\text {proximal }}\right)$

\subsection{Kinetic Data}

The ground reaction forces with their center of pressure are obtained from the AMTI force platform. The force plate outputs are processed for bias removal using basic signal averaging for smoothing the signals utilizing MATLAB software. Inverse dynamic calculations are utilized for the estimation of the hip, knee and ankle joint moments. The calculations are started from the ankle joint, continuing up to the hip joint. The ankle joint forces and moment are [19]:

$$
\begin{gathered}
\mathrm{R}_{A x}=m_{f} \cdot a_{f x}-F_{g x} \ldots(7) \\
\mathrm{R}_{A y}=m_{f} \cdot a_{f y}-F_{g y}+m_{f} \cdot g \quad \ldots(8) \\
\mathrm{R}_{\text {ankle }}=\left[\mathrm{R}_{A x}, \mathrm{R}_{A y}\right] \\
M_{A}=I_{f} \cdot \alpha_{f}-\left[r_{\text {ankle }} \times \mathrm{R}_{\text {ankle }}\right]-\left[r_{\text {ground }} \times\right. \\
\left.-F_{\text {ground }}\right]
\end{gathered}
$$

Where: $r_{\text {ground }}=\left[C O P_{c g}, 0\right]$ of the foot segment. $r_{\text {ankle }}=\left[X_{c g}, Y_{c g}\right]$ of the foot segment.

The net force and moment at the ankle proximal end causes reaction force and moment at the leg distal end in accordance with Newton's third law. As such, the knee forces and moment:

$$
\mathrm{R}_{K x}=m_{s} . a_{s x}+\mathrm{R}_{A x}
$$




$$
\begin{gathered}
\mathrm{R}_{K y}=m_{s} \cdot a_{s y}+\mathrm{R}_{A y}+m s \cdot g \\
\mathrm{R}_{\text {knee }}=\left[\mathrm{R}_{K x}, \mathrm{R}_{K y}\right] \\
M_{K}=I_{s} . \alpha_{s}+M_{A}-\left[r_{\text {knee }} \times \mathrm{R}_{\text {knee }}\right]-\left[r_{\text {a n k le }} \times\right. \\
\left.-\mathrm{R}_{\text {ankle }}\right]
\end{gathered}
$$

Where: $r_{\text {knee }}=\left[X_{c g}, Y_{c g}\right]$ of the shank segment.

The net force and moment at the knee proximal end also produces reaction force and moment at the thigh distal end. The hip forces and moment are:

$$
\begin{gathered}
\mathrm{R}_{H x}=m_{t} \cdot a_{t x}+\mathrm{R}_{K x} \ldots(13) \\
\mathrm{R}_{H y}=m_{t} \cdot a_{t y}+\mathrm{R}_{K y}+m_{t} \cdot g \ldots(14)
\end{gathered}
$$

$\mathrm{R}_{H i p}=\left[\mathrm{R}_{H x}, \mathrm{R}_{H y}\right]$

$M_{H}=I_{t} . \alpha_{t}+M_{K}-\left[r_{\text {Hip }} \times \mathrm{R}_{\text {Hip }}\right]-\left[r_{k n e e} \times\right.$

$$
\left.-\mathrm{R}_{k n e e}\right]
$$

Where: $r_{\text {Hip }}=\left[X_{c g}, Y_{c g}\right]$ of the thigh segment.

\subsection{Power and Energy}

The mechanical power at each joint is estimated as follows [17]:

Where:

$$
P_{j}=M_{j} . \omega_{j} \quad \ldots(16)
$$

$M_{j}=$ the net muscle moment measured in N.m.

$\omega_{j}=$ the joint angular velocity measured in $\mathrm{rad} / \mathrm{s}$.

The mechanical work done must be calculated from the time integral of the power curve. The work done by a muscle during a period $t_{1}$ to $t_{2}$ is [17]:

$$
\mathrm{W}=\int_{t 1}^{t 2} P d t
$$

\section{Experimental Work}

The patient attends to gait analysis laboratory placed at Al-Nahrain University before Ilizarov surgery and after surgery for examining. Before every examination the patient is given detailed instructions concerning the examination.

The patient was asked to perform walking trials on AMTI force platform is placed in the middle a six-meter wooden walkway, barefoot and at self-selected speed. Note the patient walks with aiding two crutches. From three to five trials were done and the best one was chosen. Bio-Analysis (Version2.2) is the analysis software program which is related to the AMTI force platforms and operated during and after data acquisition process. A video camera (Sony DCRSR42)which is placed at right angles to the force platforms, recorded the movements of seven markers located at specific anatomical landmarks related to the center of rotation of the lower limbs three major joints (hip, knee and ankle joints) to indicate the joint's positions and reference the subject's body simultaneously with the AMTI force platform during walking. Kinetic and kinematic data were collected for analysis and data processing using MATLAB Software 9.4.0.813654 (R2018a), shows the gait analysis system in a flowchart template.

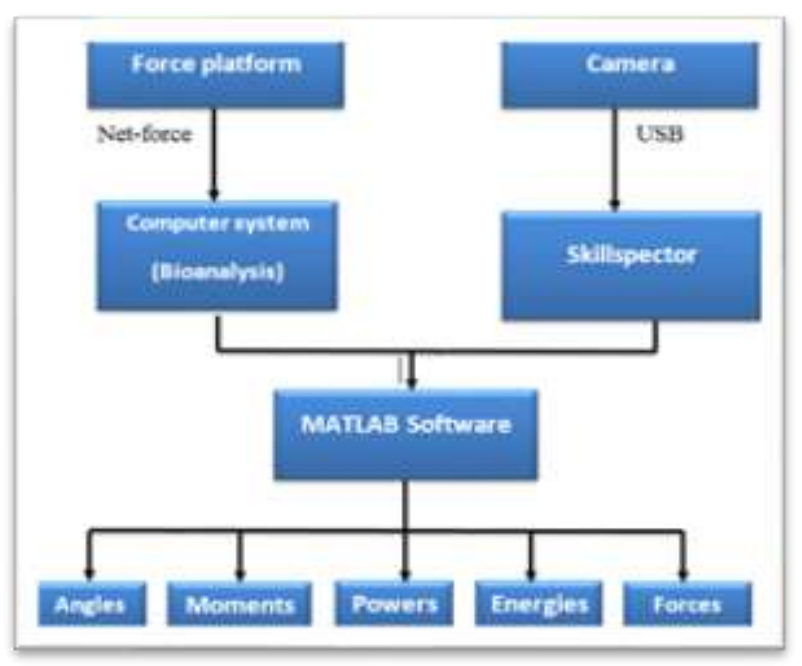

Figure(6) Flowchart of the data analysis system

\section{Results and Discussion}

Research data published on the subject of gait analysis for amputees above the knee (trans-femoral amputation) $(13,14,15)$, or gait analysis for patients treated with an Ilizarov technique $(6,16)$, while reports concerning with gait analysis for patients treated by using an Ilizarov external and they have amputation are relatively very scarce. This study dealing with the effect Ilizarov on phases of gait cycle by comparing between two stages (pre-operation and post-operation Ilizarov).

\subsection{Kinematics Gait Measures}

The presence of an Ilizarov influence on right limb (ankle, knee and hip) joint angles, where it increases the ankle angle dorsiflexion to $\left(15^{\circ}\right)$ during first half of stance phase $(0-30 \%$ of gait cycle ) in order limb and trunk stability, also it increases knee angle flexion to $\left(60^{\circ}\right)$ during initial swing to foot clearance of the floor, and it increases hip angle flexion to $\left(26.4^{\circ}\right)$ at initial swing and mid-swing (from $60 \%$ to $87 \%$ of gait cycle) by continued iliacus action.

The left ankle joint angle for pre-operation is change reverse the after operation during $(0-44 \% \mathrm{GC})$ and terminal swing, In other words; if stage of them was dorsiflexion during a certain period of the walking cycle, the other stage would be plantarflexion in the same period, the left knee joint angle flexion to $\left(18^{\circ}\right)$ for after operation at mid-stance to initiated single-limb support, while it decreases through swing phase. The left hip joint angle of post operation is higher than pre operation during (10-52\% of gait cycle) for continues as body weight advances beyond the supporting foot and the trunk remains erect, as fig.7.

\subsection{Kinetic Gait Measures}

- The moments of pre-operation stage are a lot differ from post-operation stage for three right joints at terminal swing as follow: ankle joint dorsiflexion to ($0.6)$ for post operation and dorsiflexion to $(-1.45)$ for pre-operation, knee joint extension to $(0.56)$ for postoperation and extension to (1.155) for pre-operation, and hip joint flexion to (-0.6) for post-operation and flexion to (-1.24). The moments of three left joints for pre-operation are differ from post operation at terminal swing as follow: the ankle joint dorsiflexion 
to $(-1.205)$ for pre-operation and plantarflexion to $(0.005)$ for post-operation, the knee joint extension to $(0.22)$ for pre-operation and flexion to $(-0.036)$ for post-operation, the hip joint flexion to $(-0.125)$ for pre-operation and extension to (0.151) for post operation. From above values the Ilizarov influenced on moments of right and left joints during the terminal swing phase, where this phase is represent the final phase of swing begins with a vertical tibia and ends when the foot strikes the floor .Limb advancement is completed as the leg (shank) moves ahead of the thigh, as fig. 8 .

- The power is changed for both limb joints between pre-operation and post-operation during swing phase as follow: the power of right ankle joint for preoperation is generation to (1.76) during mid-swing and absorption to (-0.089) at terminal swing, and generation to (0.71) at mid-swing and absorption to $(-0.4)$ at terminal swing for post-operation, the power of right knee joint for pre-operation is generation to $(0.15)$ and for post-operation is generation to $(0.12)$ at end initial swing and generation to (0.065) at terminal swing, the pre-operation is absorption to $(-0.69)$ at end mid-swing and the post operation is absorption to $(-0.22)$ at mid-swing, the power of right hip joint for pre-operation is absorption to $(-0.37)$ at initial swing and generation to (3.01) at end mid-swing, the post-operation is absorption to $(-0.15)$ at initial swing and generation to (1.5) at end mid-swing. The power of left ankle joint for pre-operation is generation to (0.11) at mid-swing and for the post-operation is generation to $(0.015)$ at end initial swing, the power of left knee for pre-operation is absorption to $(-0.047)$ at end initial swing and generation to (0.164) at terminal swing, the post-operation is absorption to ($0.01)$ at end initial swing and generation to (0.001) at end mid-swing, the power of left hip joint for preoperation is opposite after operation during (0-30\%) and $(78-100 \%)$ of gait cycle. From above values noting to the absorption power of post-operation for right knee and hip joints are greater than the absorption power of pre-operation, that means the Ilizarov made the knee and hip joints consume more

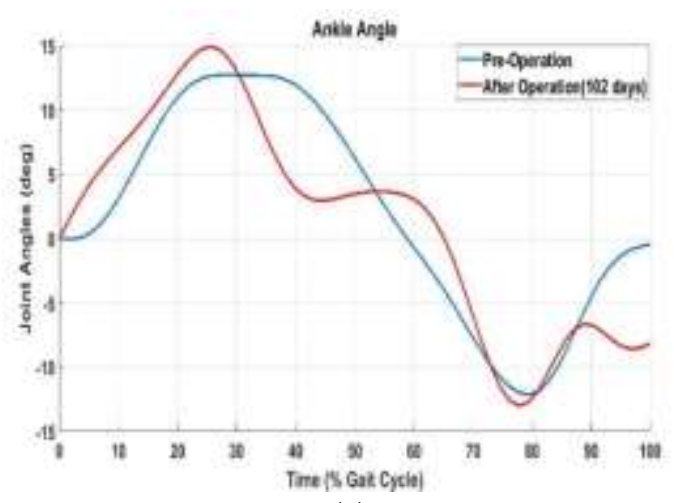

(a) power during swing phase. Also the power of left hip joint is affected with Ilizarov during the first half of stance phase and second half of swing phase, as fig.9.

- The horizontal force of three right joints for post operation are higher than the horizontal force for preoperation during (26-100\%GC). There are differences between two stages for horizontal force of left limb joints during gait cycle; but these differences for ankle joint more than knee, then hip joints, as fig.10.

- The vertical force of three right limb joints for after operation stage is higher than the pre-operation stage through the stance phase. In contrast, the preoperation stage is higher than after the operation stage during the swing phase, except for the end swing phase. The vertical force of left limb joints for the pre-operation stage is higher than after the operation stage during (44-100\%GC). In contrast, the preoperation stage and after operation stage during (0$44 \% \mathrm{GC}$ ) are convergent in value for ankle joint. And appear to differ between two stages for knee and hip joints during the same this period, as fig. 11 .

\subsection{Energy Expenditure}

The energy is increased during the swing phase for right (ankle and hip) joints and left knee and hip joints for both stages. There are differences between two stages for the right knee and left ankle joints through the gait cycle, as fig. 12 .

\section{Conclusion}

1-The moments, powers, and energies expenditure for both limbs in two cases (pre and after the operation) changes significantly during the swing phase; this indicates to swing phase is more affected when the Ilizarov device and the prosthesis found together of the same patient.

2- The horizontal force of the joints of both limbs (left and right) changes significantly in the ankle joint when placing the Ilizarov device, it means the patient depends a lot on the ankle joint in walking.

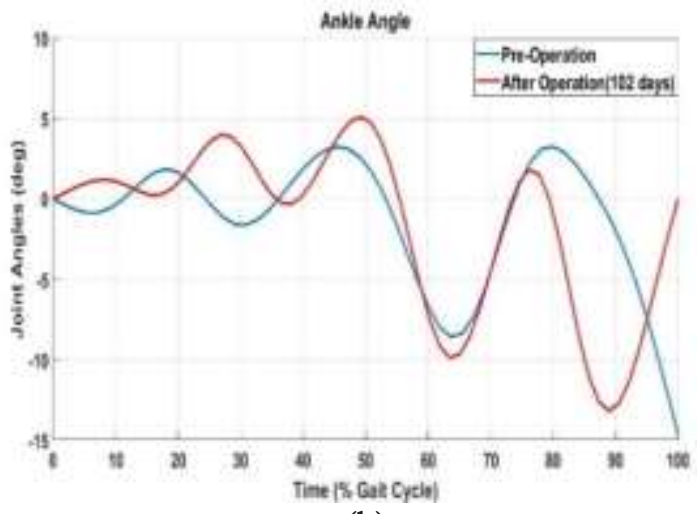

(b) 


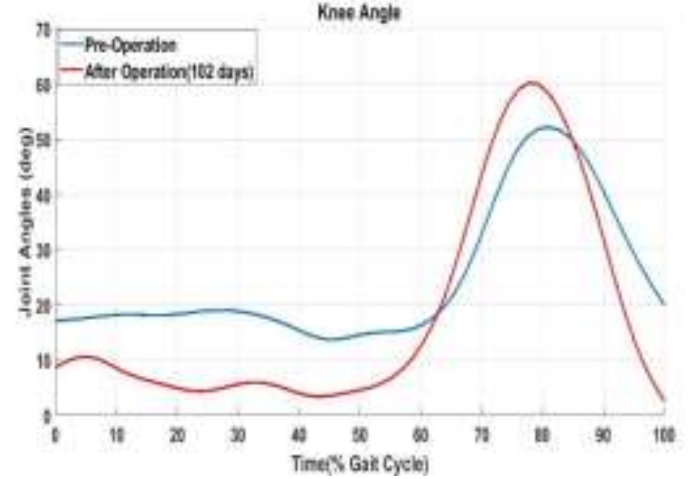

(c)

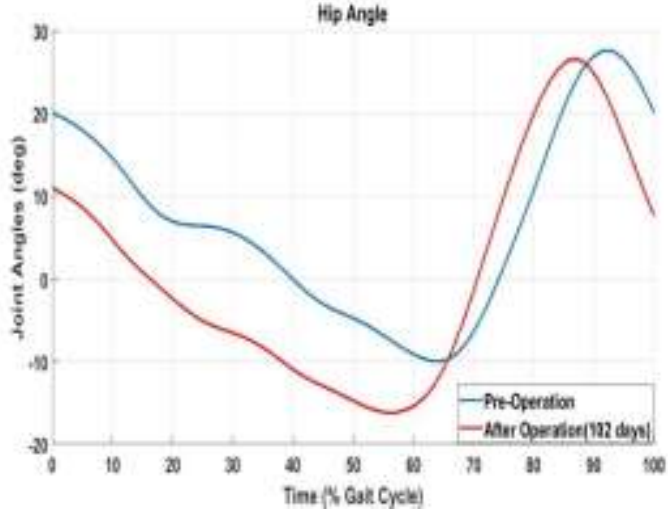

(e)

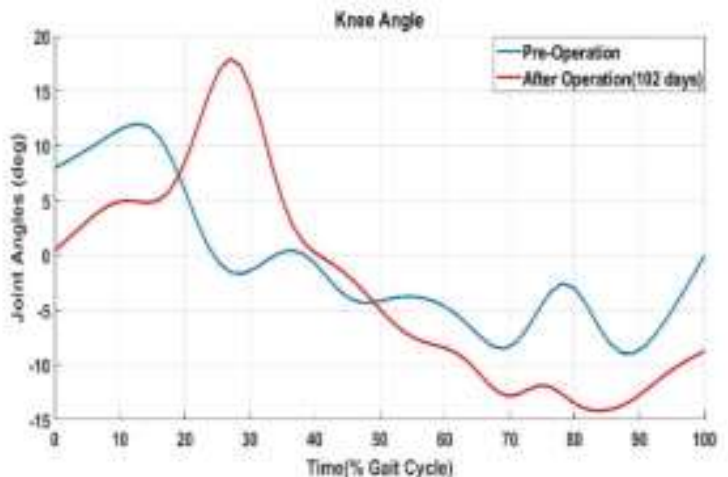

(d)

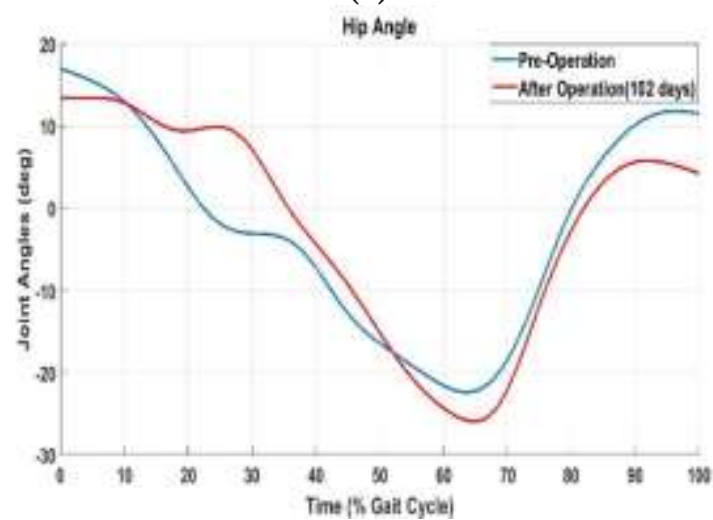

(f)

Figure (7): Sagittal plane ankle, knee and hip joint angles during gait cycle of patient: (i) a, c and e right limb; (ii) b, $\mathrm{d}$ and $\mathrm{f}$ left limb.

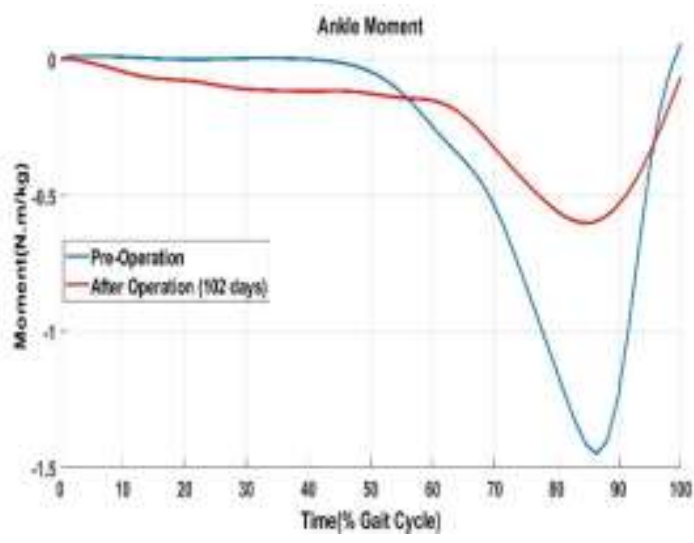

(a)

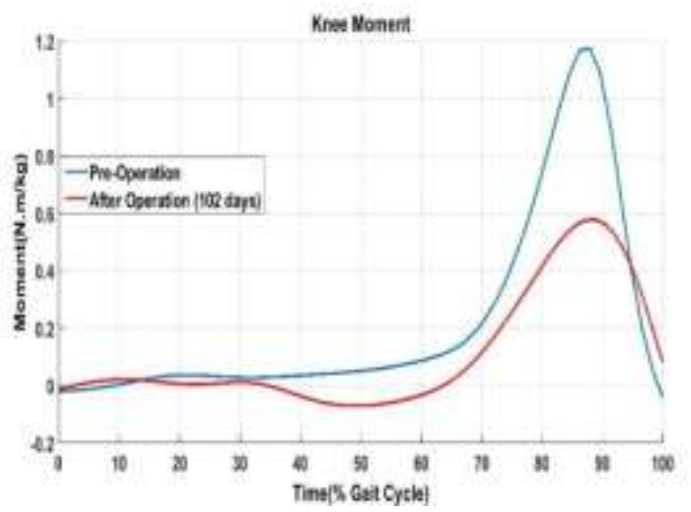

(c)

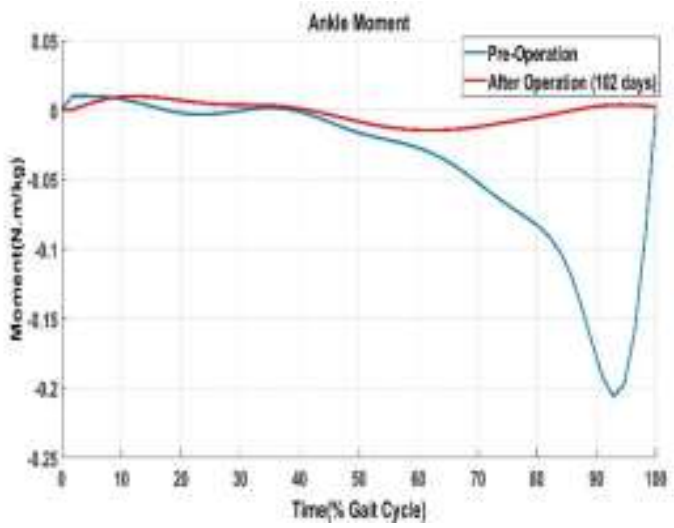

(b)

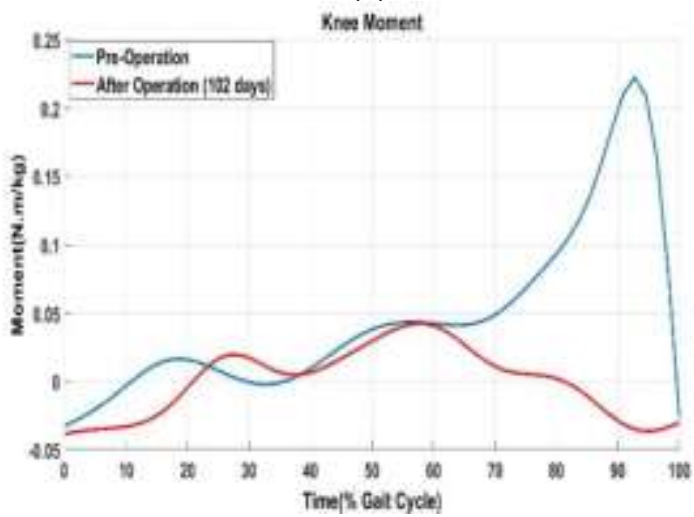

(d) 


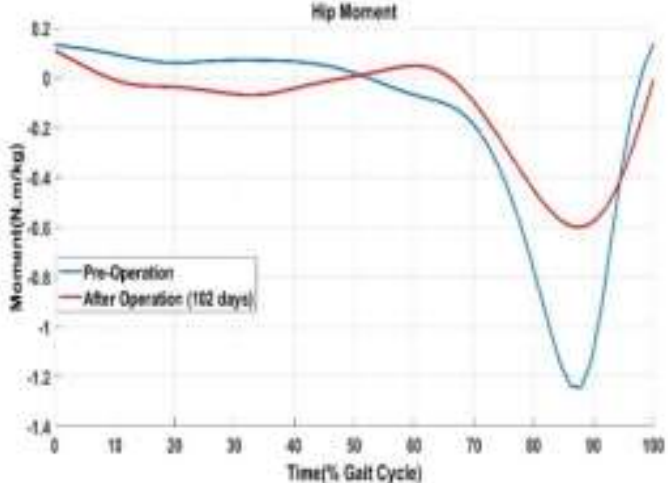

(e)

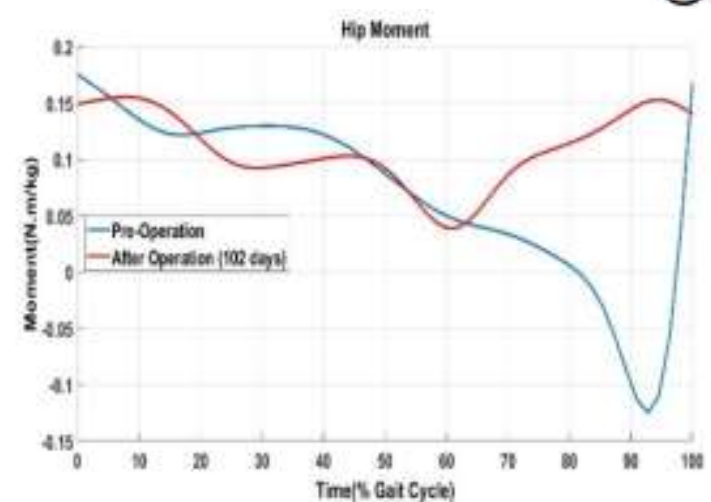

(f)

Figure (8): Sagittal plane ankle, knee and hip joint moments during gait cycle of patient: (i) a, c and e right limb; (ii) b, $d$ and $f$ left limb.

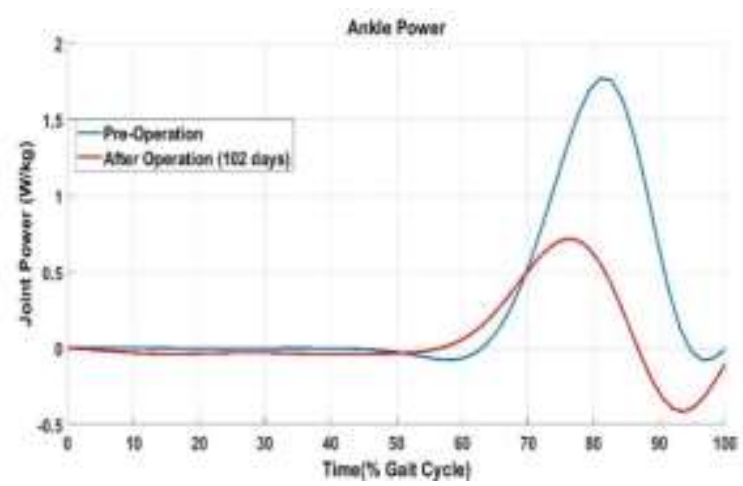

(a)

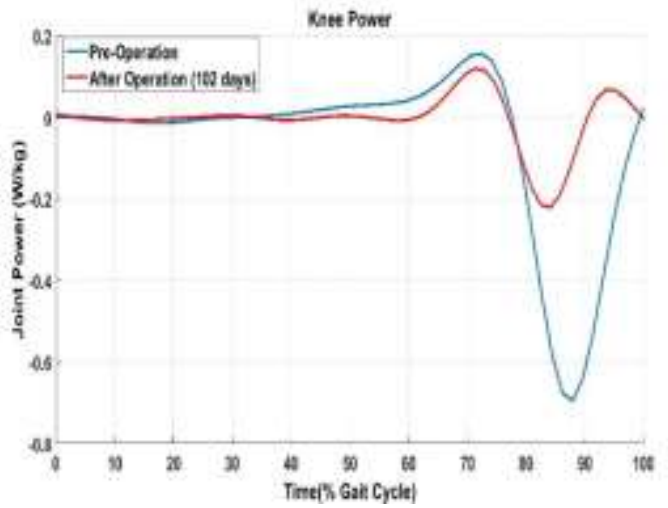

(c)

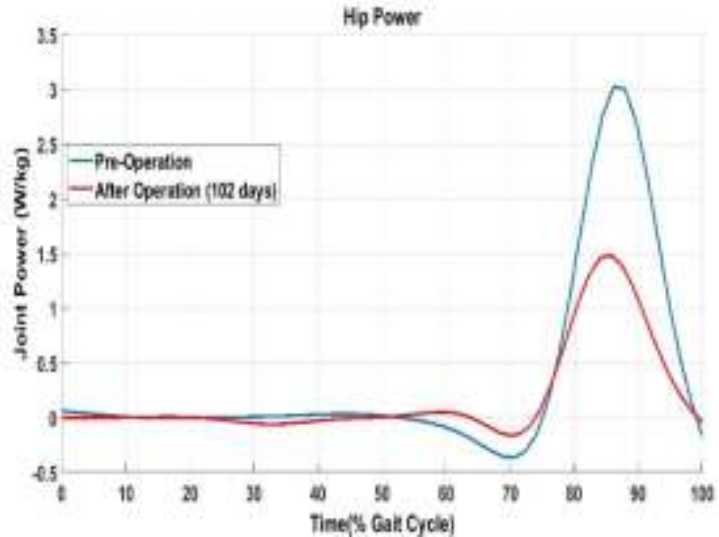

(e)

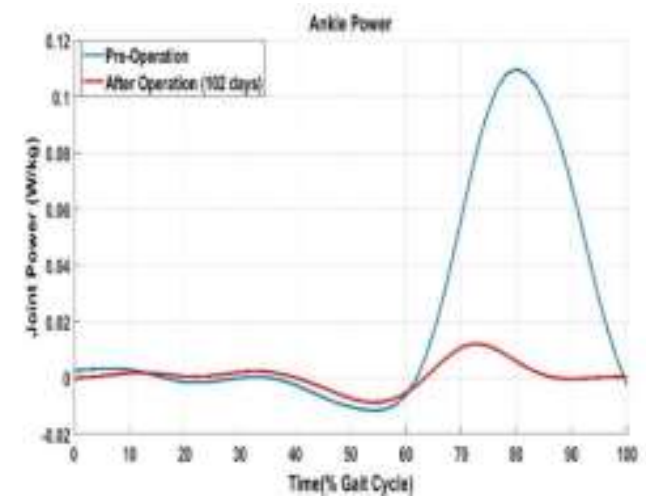

(b)

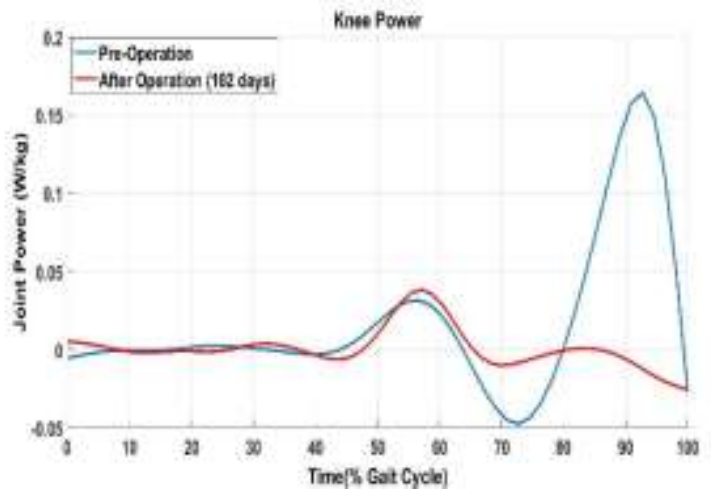

(d)

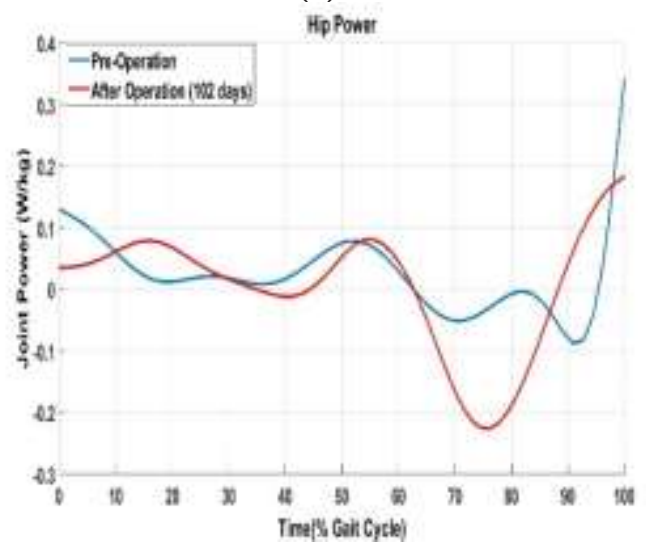

(f)

Figure (9) Sagittal plane ankle, knee and hip joint powers during gait cycle of patient: (i) a, c and e right limb; (ii) b, $\mathrm{d}$ and $\mathrm{f}$ left limb. 


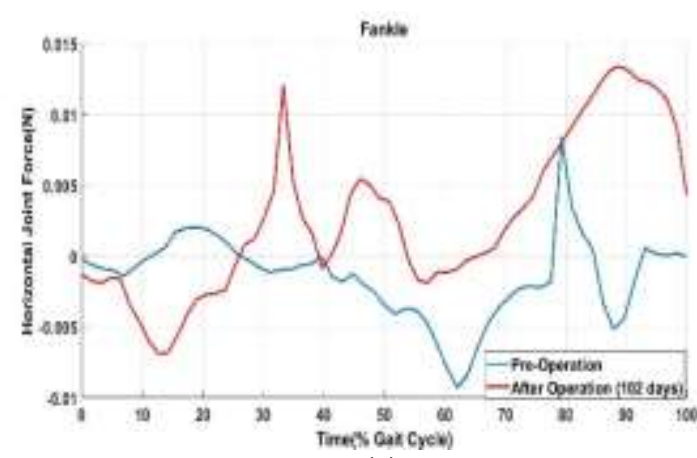

(a)

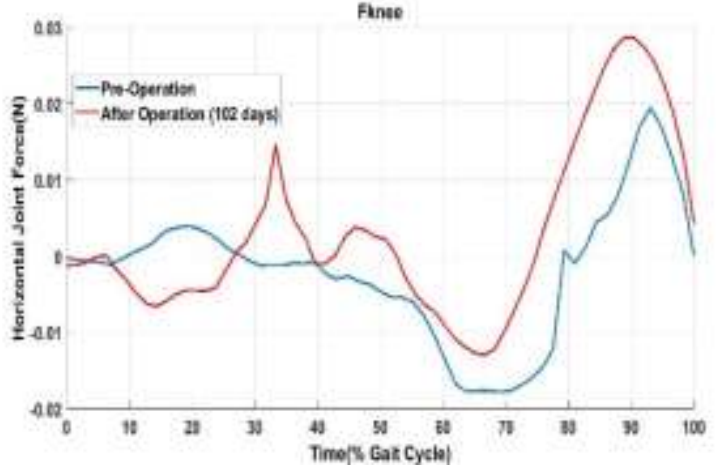

(c)

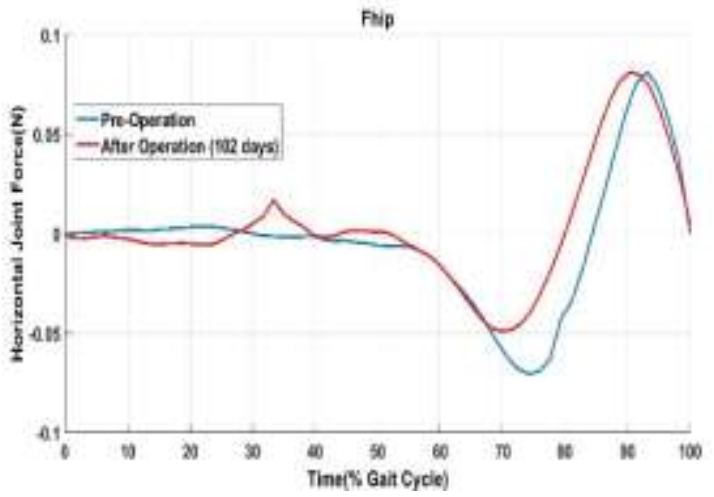

(e)

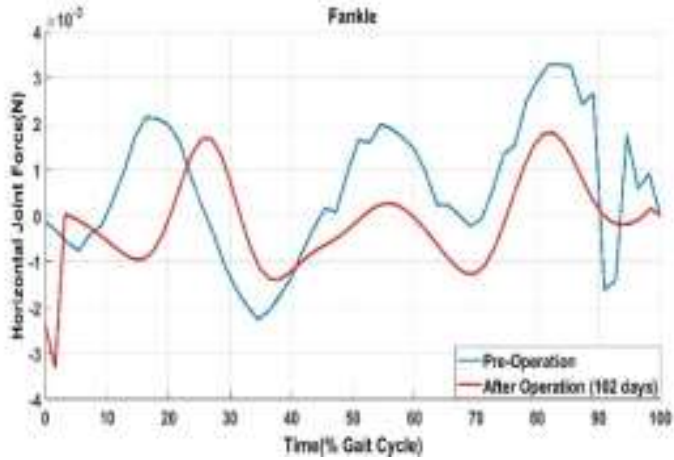

(b)

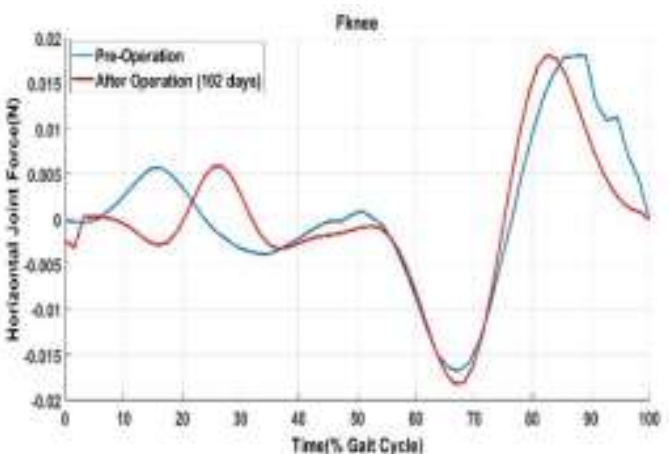

(d)

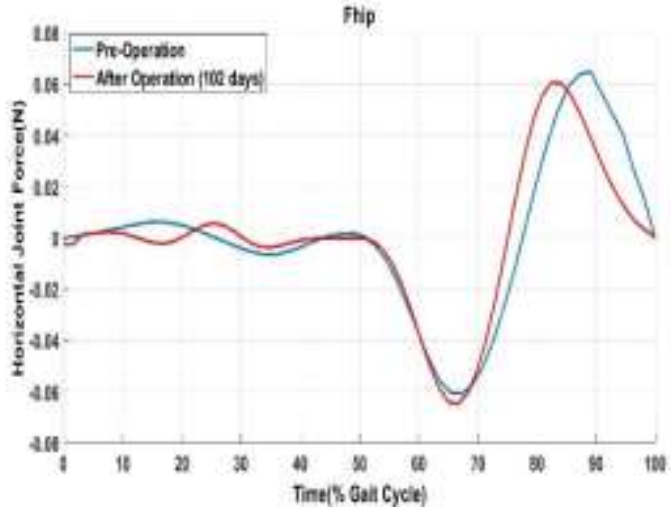

(f)

Figure (10) Sagittal plane ankle, knee and hip joint horizontal forces during gait cycle of patient: (i) a, c and e right limb; (ii) b, d and fleft limb.

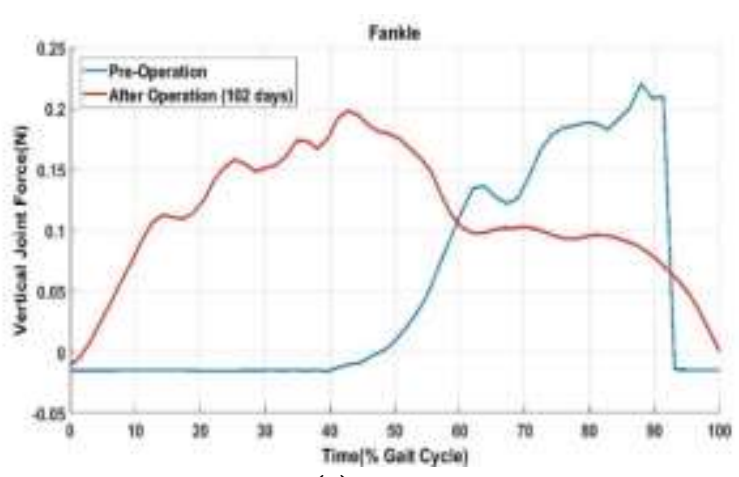

(a)

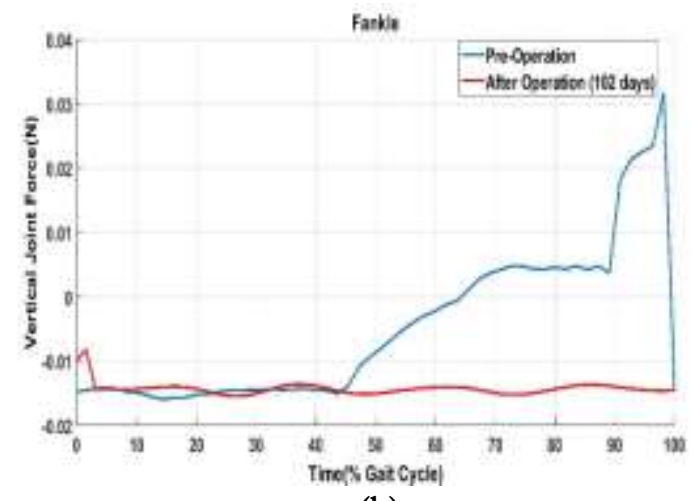

(b) 


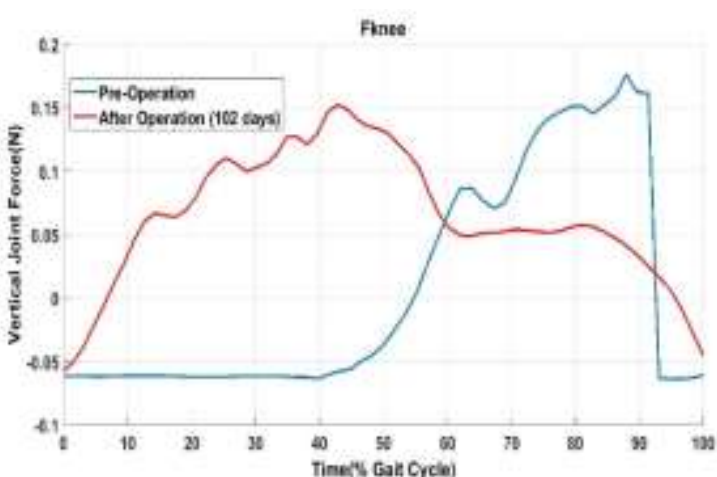

(c)

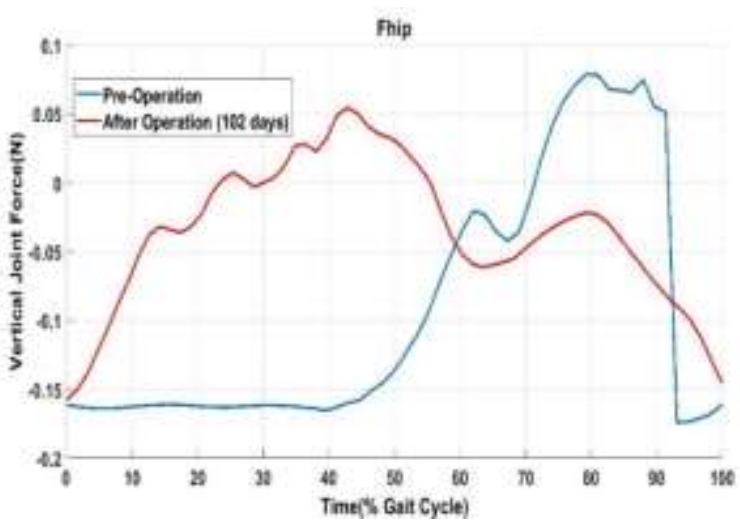

(e)

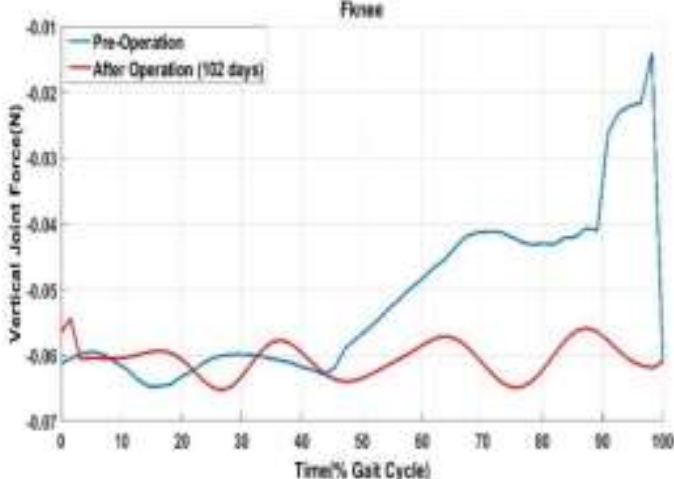

(d)

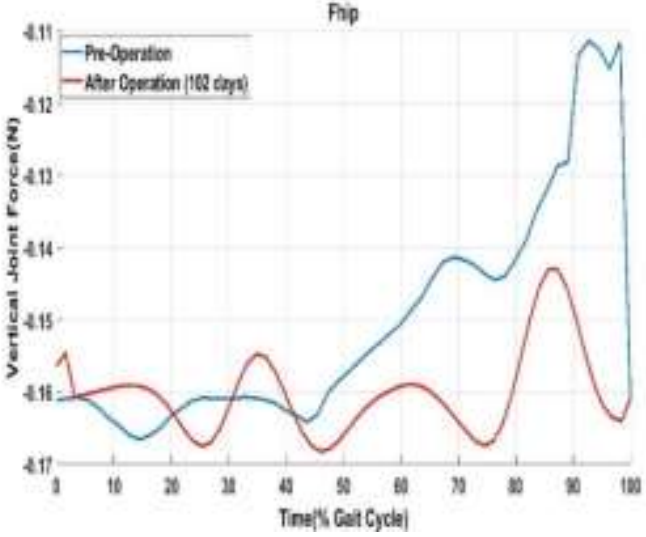

(f)

Figure (11) Sagittal plane ankle, knee and hip joint vertical forces during gait cycle of patient: (i) a, c and e right limb; (ii) b, d and fleft limb.

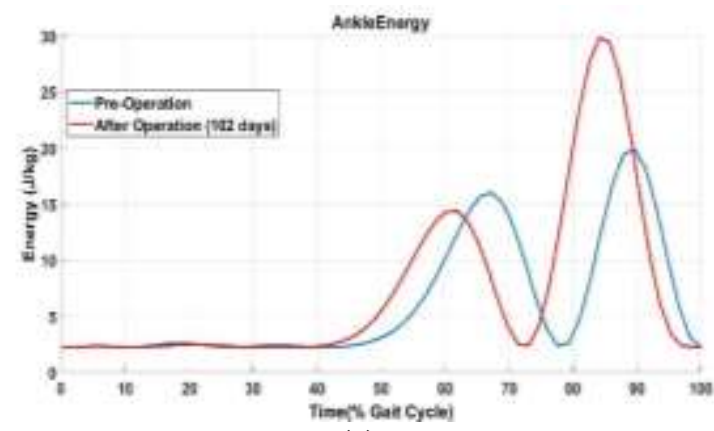

(a)

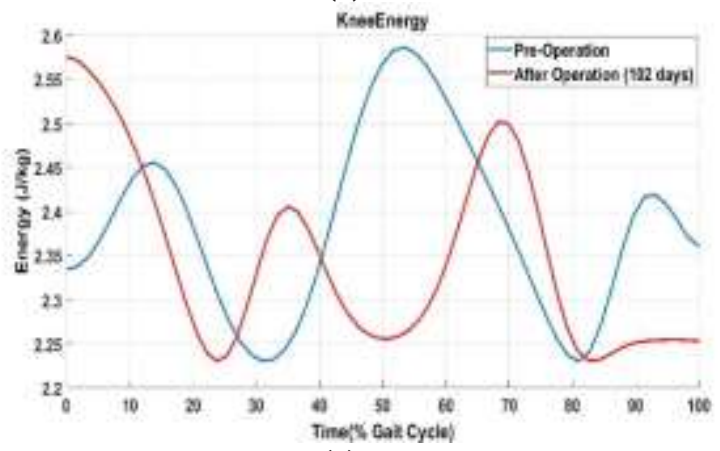

(c)

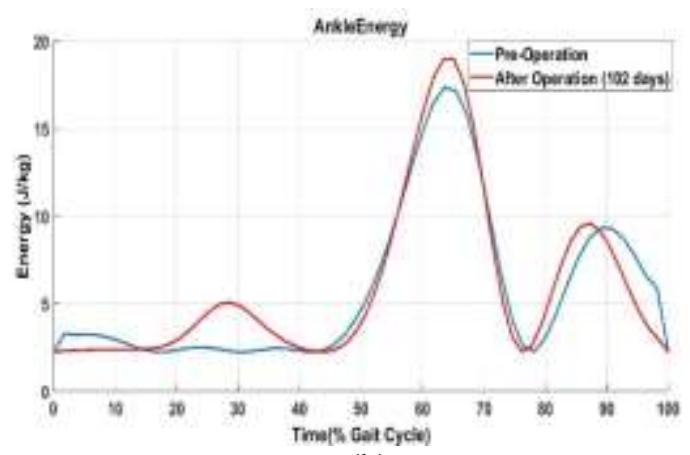

(b)

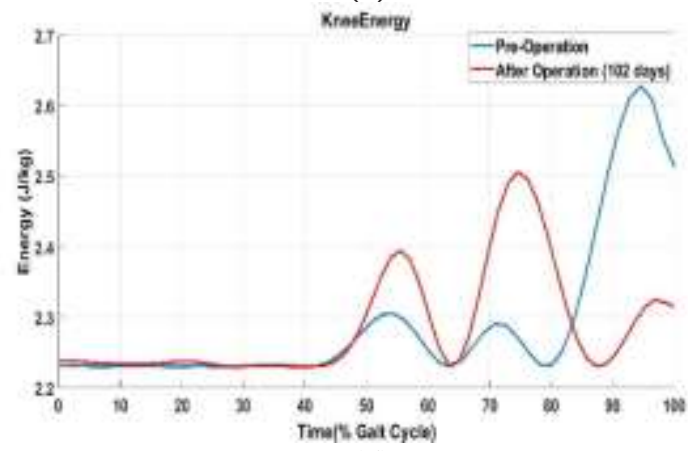

(d) 


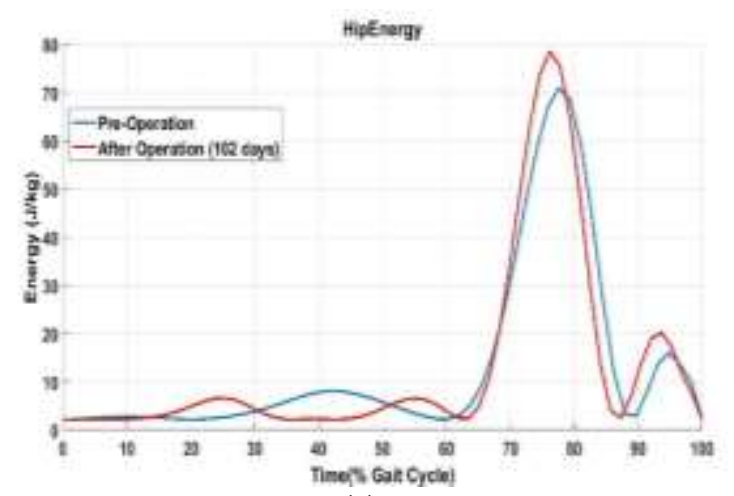

(e)

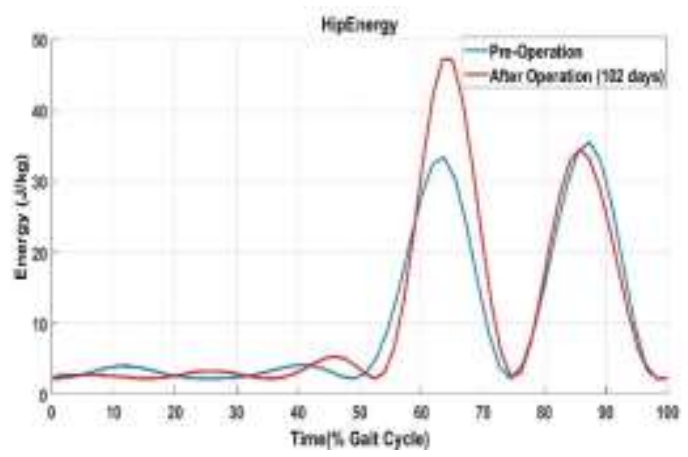

(f)

Figure (12) Sagittal plane ankle, knee and hip joint energies during gait cycle of patient: (i) a, c and e right limb; (ii) b, $d$ and $f$ left limb.

\section{References:}

[1] Moss, D. P. Moss and N. C. Tejwani, "Biomechanics of external fixation", Bulletin of the NYU hospital for joint diseases, 65(4), 294-9, (2007).

[2] B. Fleming, D. Paley and T. Kristiansen, et al.,"A biomechanical analysis of the Ilizarov external fixator", Clin Orthop Relat Res; 241: 95-105, 1989.

[3] AE. Goodship and J. Kenwright, "The influence of induced micromovement upon the healing of experimental tibial fractures", J Bone Joint Surg Br; 67(4): 650-655, 1985.

[4] C. Etter, C. Burri and L. Claes, et al., "Treatment by external fixation of open fractures associated with severe soft tissue damage of the leg", Biomechanical principles and clinical experience. Clin Orthop Relat Res; 178: 80-88, 1983.

[5] JW. Busse, E. Morton and C. Lacchetti, et al., "Current management of tibial shaft fractures: a survey of 450 Canadian orthopedic trauma surgeons", Acta Orthop; 79(5): 689-694, 2008.

[6] R. B. Layton, T. D. Stewart, P. Harwood and N. Messenger, "Biomechanical analysis of walking gait when simulating the use of an Ilizarov external fixator", Proceedings of the Institution of Mechanical Engineers, Part H: Journal of Engineering in Medicine, 232(6), 628-636, (2018).

[7] K. Sansam, V. Neumann, R. O'Connor and B. Bhakta, "Predicting walking ability following lower limb amputation: a systematic review of the literature", Journal of rehabilitation medicine, 41(8), 593-603, (2009).

[8] JP. Pell, PT. Donnan, FG. Fowkes and CV. Ruckley, "Quality of life following lower limb amputation for peripheral arterial disease", Eur J Vasc Surg; 7: 448451, 1993.

[9] D.Datta, PN. Nair and J. Payne, "Outcome of prosthetic management of bilateral lower-limb amputees", Disabil Rehabil; 14: 98-102, 1992.
[10] C. Collin, DT. Wade and GM. Cochrane, "Functional outcome of lower limb amputees with peripheral vascular disease", Clin Rehabil; 6: 13-21, 1992.

[11] F. Gerhards, I. Florin and T. Knapp, "The impact of medical, reeducational, and psychological variables on rehabilitation outcome in amputees", Int J Rehab Res; 7: 379-388, 1984.

[12] H. Cochrane, K. Orsi and P. Reilly, "Lower limb amputation Part 3: Prosthetics-a 10 year literature review", Prosthetics and orthotics international, 25(1), 21-28., (2001).

[13] E.N. Zuniga, L.A. Leavitt, J.C. Calvert, J. Canzoneri and C.R. Peterson, "Gait patterns in above-knee amputees,"Arch Phys Med Rehabilitation, 53:373-382, 1972.

[14] U. James and K. Oberg, "Prosthetic gait pattern in unilateral above-knee amputees," Scand J Rehabil Med, 5:35-50, 1973.

[15] M.P. Murrary, S.B. Sepic, G.M. Gardner and L.A. Mollinger, "Gait patterns of above-knee amputees using constant-friction knee components," Bull Prosthet Res, 17(2):35-45, 1980.

[16] D. Szydłak, A. Famuła, T. S. Gaździk, W. GallertKopyto, J. Sołtys and R. Plinta, "Gait analysis in children after the lengthening of the lower limb by the Ilizarov technique", In Annales Academiae Medicae Silesiensis (Vol. 71, pp. 252-264), (2017).

[17] D. A. Winter, "Biomechanics and motor control of human movement", John Wiley \& Sons, (2009).

[18] D.A. Winter, "The Biomechanics and Motor Control of Human Movement", 2nd edition, Springer New York, ISBN: 0-88898-105-8, 1990.

[19] T. S. Buchanan, "Estimation of Muscle Forces and Joint Moments Using a Forward-Inverse Dynamics Model", Medicine and Science in Sport and Exercise, pp. 1911-1916, 2005. 